\title{
A Rare Cause of Ileus: Gallstone
}

\author{
Nadir Bir Ileus Nedeni: Safra Tașı
}

Bülent Gürbüz, Fatih Büyüker, Tuba Atak, Sinan Aslan, Haydar Yalman, Rafet Yig̃itbașı

Göztepe Eg̃itim ve Araștırma Hastanesi, 3. Genel Cerrahi Klinig̃i, İstanbul, Türkiye

\begin{abstract}
Gallstone ileus is a rare complication of biliary stone. A 89-yearold female patient admitted to our emergency departmant with abdominal pain, distansion and vomiting. Laparatomy was performed by reason of mechanic intestinal obstruction. In this report we present a case with gallstone ileus diagnosed preoperatively and treated by drawing the gallstone through the intestine to the anus without enterotomy.
\end{abstract}

Keywords: Gallstone, ileus, treatment

Received: 05.04.2011 Accepted: 13.05.2011

\section{ÖZET}

Safra tașı ileusu, safra tașının nadir görülen bir komplikasyonudur. Seksen dokuz yașında kadın hasta karın ag̃rısı, kusma, șișkinlik șikayetleri ile acil birimimize başvurdu ve hastaya mekanik intestinal obstruksiyon nedeni ile laparatomi uygulandı. Bu yazıda, preoperatif olarak tanısı konulan ve enterotomiye gerek kalmadan taşın distale dog̃ru itilerek çıkarıldıg̃ ı bir safra tașı ileusu olgusu sunulmaktadır.

Anahtar Kelimeler: Safra tașı, ileus, tedavi

Geliş Tarihi: 05.04.2011 Kabul Tarihi: 13.05.2011

\section{Giriş}

Safra tașı ileusu, safra kesesi veya safra yolları ile duodenum, mide ya da kolon arasında meydana gelen fistüle bag̃lı olarak safra taşlarının intestinal sisteme geçerek obstruksiyona neden olması ile meydana gelmektedir (1, 2). Safra tașı ileusu tüm intestinal obstruksiyonların sadece \%1-3'ünü olușturmaktadır (3). Tüm kolelitiazis olgularının \%0.3-0.5'inde görülmektedir ve kadın erkek oranı 1-1.6:1'dir (3,4). Bilioenterik fistül nedeni ile intestinal sisteme geçen safra tașlarının \%80'i sorun olușturmadan dışarı atılmaktadır (4). Tanıda düz karın grafisi, tüm batın ultrasonografisi, bilgisayarlı batın tomografisi, gastroskopi ve kontrastlı üst gastrointestinal inceleme yöntemleri kullanılmaktadır (5). Tedavi seçenekleri arasında enterolitotomi, tek evreli cerrahi (taș çıkarımı, kolesistektomi, fistül trakt eksizyonu) veya iki evreli cerrahi (enterolitotomi ve biliyer trakt cerrahisi) sayılmaktadır $(5,6)$. Bu sunumda operasyon öncesinde tanısı konulan ve enterotomiye gerek kalmadan tașın distale dog̃ru itilerek transanal olarak çıkarıldı̃̃ı bir safra tașı ileusu olgusu sunulmaktadır.

\section{Olgu Sunumu}

Seksen dokuz yașında kadın hasta yaklașık 5 gündür devam eden karın ag̃rısı, bulantı, kusma, gaita çıkaramama șikayetleri ile acil servisimize bașvurması üzerine klinig̃imize yatıııldı. Fizik muayenede batın distandü ve palpasyonda yaygın hassasiyet saptandı. Oskültasyonda batın dört kadranda da barsak sesleri alınamadı, perküsyonda batın dört kadranda timpanizm tespit edildi. Rektal tuşede ampulla boș idi ve palpabl bir kitle saptanmadı. Özgeçmișinde hipertansiyon ve 3 yıl önce geçirilmiş koroner anjiografi hikayesi vardı. Ayakta direkt batın grafisinde opak görünüm ve hava sıvı seviyelenmeleri mevcuttu (Resim 1). Tüm batın ultrasonografisinde safra kesesinde safra kumu ile perihepatik, perikolesistik ve barsak ansları arasında minimal serbest mayi oldug̃u tespit edildi. Kontrastlı batın tomografisinde safra kesesi içerisinde hava imajları olan tübüler yapılar tespit edildi. Intrahepatik 
safra yollarında belirginleșme ve hava izlendi. İnce barsak anslarının dilate oldug̃u ve sag̃ alt kadranda crista iliaca superior kranial komșulug̃unda ileal ans içerisinde yaklaşık $2 \mathrm{~cm}$ çapında dens imaj kalkül olarak deg̃erlendirildi. Bu bulgular eșlig̃inde hastada ilk planda bilier bir patolojiye bag̃lı mekanik intestinal obstruksiyon düșünüldü ve akut batın kliniõi gelișmesi üzerine operasyon kararı alındı. Laparotomide ince barsak anslarının dilate oldug̃u, sag̃ üst kadranda safra kesesi, duedonumun ve omentumun bir gato șeklinde birbiri ile birleștig̃i, sigmoid kolonda intraluminal yerleșimli yaklașık $3 \times 2 \mathrm{~cm}$ çapında, mobil, sert, parmak ile yapılan manüplasyonlarla yer deg̃iștirebilen kitle saptandı (Resim 2). Bu kitlenin safra tașı olabileceg̃ine karar verildi ve mobil olmasından dolayı distale dog̃ru el yardımı ile nazikçe ilerletilerek transanal yolla dıșarı çıkarıldı (Resim 3A, B). Enflame görünümde olan ve bir kolesistoduedonal fistül ile uyumlu görünen sag̃ üst kadrandaki gato yapmıș dokulara hastanın yașı ve komorbid faktörleri düșünülerek herhangi bir girișim uygulanmadı. Postoperatif dönemde 5. gün problemi olmayan hasta taburcu edildi.
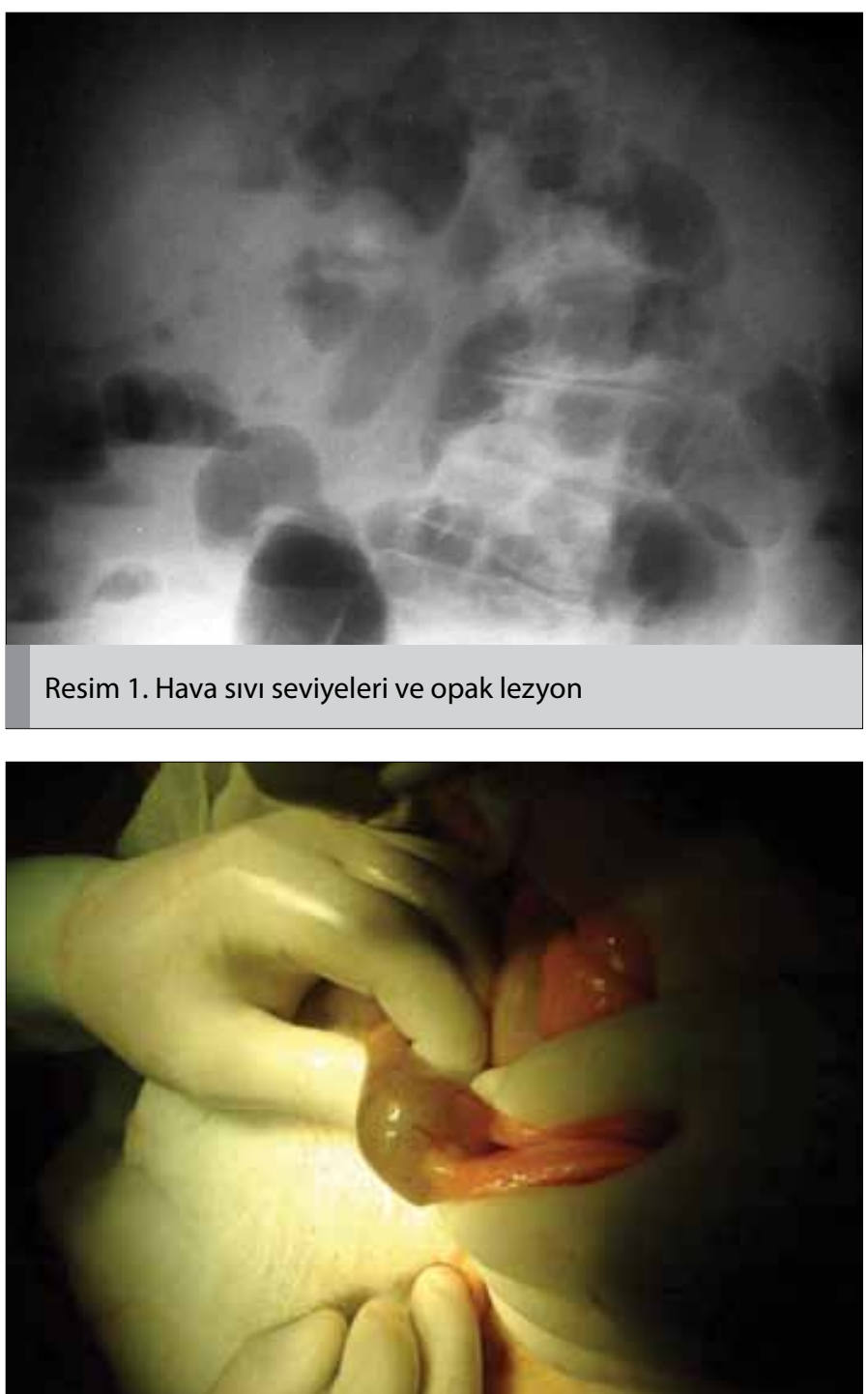

Resim 2. Sigmoid kolonda yaklaşık 2*3 cm'lik sert kitle

\section{Tartışma}

Safra tașı ileusu, safra kesesi veya safra yolları ile duodenum, mide ya da kolon arasında meydana gelen fistüle bag̃lı olarak safra tașlarının intestinal sisteme geçmesi ve obstruksiyona neden olması ile meydana gelmektedir $(1,2)$. Olușan bu fistüller içerisinde en sık kolesistoduodenal fistül görülmektedir (Tablo 1). Safra tașına bag̃lı mekanik intestinal obstrüksiyonlar tüm intestinal obstruksiyonların sadece \%1-3'ünü olușturmaktadır (3). Genellikle ileri yașlarda görülmektedir (7). Ayakta direkt karın grafisi mekanik intestinal obstrüksiyonu göstermede ilk adım tetkiktir. Komplet olmayan obstrüksiyonların ayırıcı tanısında ultrasonografi ve bilgisayarlı tomografiden faydalanılır $(7,8)$. Safra tașı ileusundan șüphe ediliyorsa fistülü göstermede kontrastIı gastrointestinal grafiler çekilebilmektedir (4). Safra tașı ileusunda klinik belirti ve bulgular nonspesifik oldug̃undan kesin tanı sıklıkla operasyon esnasında konmakta olup yayınlanan serilerin \%43'ünde tanı preoperatif konabilmiștir. Obstruksiyon en sık terminal ileumda (\%70) daha az sıklıkla proximal ileum, jejenum, kolon ve duodenumda meydana gelmektedir (9). Çapı 2.5 cm'yi geçen taşlarda obstrüksiyon olușturma șansı yüksektir (4).

Kesin tanısı preoperatif dönemde konulabilen safra tașı ileuslarında endoskopik litotripsi bir tedavi alternatifi olușturmaktadır (10). Tedavi seçenekleri arasında enterotomi, tek evreli cerrahi (taş çıkarımı, kolesistektomi, fistül trakt eksizyonu) veya iki evreli cerrahi (enterotomi ve biliyer trakt cerrahisi) sayılmaktadır $(5,6)$. Ayrıca laparoskopik tanı ve tedavi de uygulanabilen bir yöntemdir $(5,11)$. Bazı yazarlar unstabil hastalarda sadece enterotomi ile tek evreli cerrahiyi önerseler de çog̃u yazar ilk seçenek olarak sadece enterotomi, sonra hastanın klinik takibinde hasta semptomatikse veya izlemde komplikasyon gelișmișse ikinci operasyonu savunmaktadırlar (3). Safra tașı ileusunda obstrüksiyonun giderilmesi tedavinin esasını olușturmaktadır. Acil tedavide tek ve iki evreli cerrahi stratejiyi karșılaștıran çalıșmalar her iki ișleminde sıfıra yakın mortaliteyle güvenli yapılabileceg̃ini belirtmektedir (6). Genel anlamda literatüre bakıldı̃̃ında, tek evreli tedavide mortalite bazı çalıșmalarda \%19'a kadar çıkabilirken, iki evreli operasyonlarda da mortalite hiç izlenmeyebilmektedir (4, 5). Reissner ve Cocher'in 1000 hastadan fazla olan serisinde tek evreli cerrahi prosedürünün mortalite oranını \%16.9, sadece enterotomi yapılanın ise \%11.7 olarak tespit etmișlerdir. Bununla birlikte sadece enterotomi yapılan hastaların \%10'unda bilier sistem semptomları nedeniyle yeniden operasyona ihtiyaç duymuşlardır. Fistül tamiri yapılan hastalarda sadece enterotomi yapılan hastalara nazaran daha yüksek mortaliteye neden oldug̃u tespit edilmiștir. Illeri yaș, yandaș hastalıklar, Sıvı ve elektrolit dengesizlig̃i ve tanıda gecikme nedeniyle \%12-18 oranında mortalite görülebilmektedir $(11,12)$. Ayrıca aynı anda fistül

Tablo 1. Fistül lokalizasyonları ve görülme sıklığı

\begin{tabular}{lc}
\hline Fistül lokalizasyonu & Görülme sıklığı \\
\hline Kolesistoduodenal & $\% 76$ \\
\hline Kolesistokolik & $\% 11$ \\
\hline Kolesistogastrik & $\% 6$ \\
Koledokoduodenal & $\% 4$ \\
Kolesistokoledokal & $\% 3$
\end{tabular}



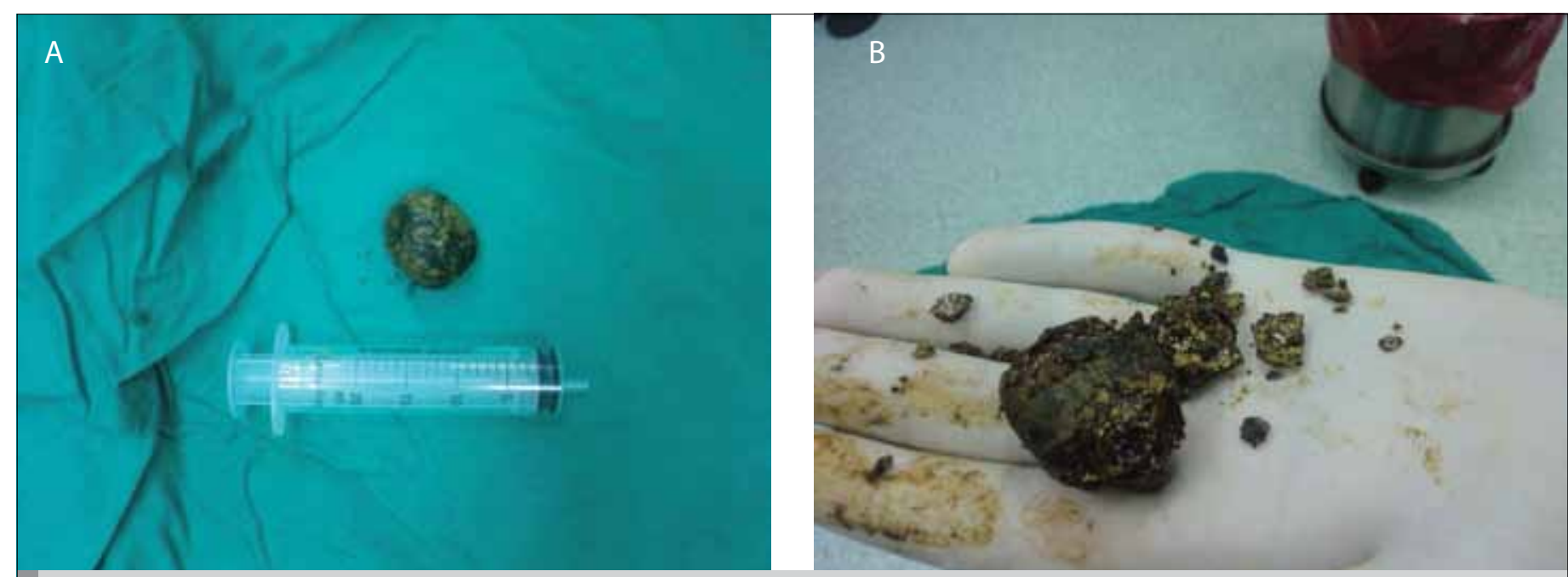

Resim 3A, B. İleusa neden olan safra taşının görüntüsü

tamiri ve kolesistektomi yapılması yeniden operasyon, kolanjit, kolesistit, fistülün persiste etmesi ve ileus gibi komplikasyonları azaltsa da tek evreli cerrahi prosedür (enterotomi, fistül tamiri, kolesistektomi) daha yüksek mortaliteye neden olmaktadır. Bazı bireysel faktörlere (yaş, klinik stabilite gibi) göre her hastaya göre uygun tedavi seçeneg̃i seçilmelidir (3). Bu olguda biz hastanın yașını, genel durumunu, komorbid faktörlerini, operasyon esnasındaki bulgularını göz önünde bulundurdug̃umuzda ve tașın mobil oldug̃unun tespit edilmesi üzerine tașı anüsten çıkarmayı tercih ettik.

\section{Sonuç}

Safra tașı ileusunun, morbidite ve mortalite açısından oldukça yüksek seyredebilmesi nedeniyle, ileusun tanısal antiteleri içinde bulunması gerekmektedir. Ayrıca safra tașı ileuslarında nadir de olsa tașın distale dog̃ru hareket edebileceg̃i akılda bulundurulmalıdır. Böylece enterotominin hastaya yükleyeceg̃i morbidite ve mortalitenin önlenebileceg̃inin göz önünde bulundurulması gerekmektedir.

\section{Çıkar çatışması}

Yazarlar herhangi bir çıkar çatıșması bildirmemișlerdir.

\section{Kaynaklar}

1. Rodriguez JC, Casado F, Femandez MJ, Morales DJ, Naranjo A. Cholecystectomy and fistula closure versus enterolithotomy alone in gallstone ileus. Br J Surg 1997; 84: 634-7. [CrossRef]
2. Matur R, Yucel T, Gurdal SO, Akpinar A. Bouveret'S syndrome: gastric outlet obstruction by a gallstone. Ulus Travma Derg 2002; 8: 179-82.

3. Martínez Ramos D, Daroca José JM, Escrig Sos J, Paiva Coronel G, Alcalde Sánchez M, Salvador Sanchís JL. Gallstone ileus: Management options and results on a series of 40 patients. Rev Esp Enferm Dig 2009; 101: 117-20.

4. Kasahara Y, Umemura H, Shiraha S, Kuyama T, Sakata K, Kubota H. Gallstone ileus. Review of 112 patients in the Japanese literature. Am J Surg 1980; 140: 437-40. [CrossRef]

5. Clavien PA, Richon J, Burgan S, Rohner A. Gallstone ileus. Br J Surg 1990; 77: 737-42. [CrossRef]

6. Tan YM, Wong WK, Ooi LL. A comparison of two surgical strategies for the emergency treatment of gallstone ileus. Singapore Med J 2004; 45 69-72.

7. Gaiani S, Serra C, Cervellera M, Campione O, Bolondi L, Miglioli M. Gallstone ileus in Caroli's disease. Am J Gastroenterol 2000; 95: 3642-3. [CrossRef]

8. Scarpa FJ, Borges J, Mullen D. Gallstone ileus. Am J Surg 2000; 180: 99. [CrossRef]

9. Khaira HS, Thomas DR. Gallstone emesis and ileus caused by common hepatic duct-duodenal fistula. Br J Surg 1994; 81: 723. [CrossRef]

10. Bourke MJ, Schheider DM, Haber GB. Electrohydraulic lithotripsy of gallstone causing gallstone ileus. Gastrointest Endosc 1997; 45: 521-3. [CrossRef]

11. Allen JW, McCurry T, Rivas H, Cacchione RN. Totally laparoscopic management of gallstone ileus. Surg Endosc 2003; 17: 352. [CrossRef]

12. Doko M, Zovak M, Kopljar M, Glavan E, Ljubicic N, Hochstädter H. Comparison of surgical treatments of gallstone ileus:preliminary report. World J Surg 2003; 27: 400-4. [CrossRef] 